\title{
Application of Biosynthesized Silver Nanoparticles Against a Cancer Promoter Cyanobacterium, Microcystis aeruginosa
}

\author{
Mostafa Mohamed El-Sheekh*, Hala Yassin El-Kassas
}

\begin{abstract}
Background: Nanotechnology opens new applications in many fields including medicine. Among all metallic nanoparticles, silver nanoparticles (silver NPS) have proved to be the most effective against a large variety of organisms including toxic cyanobacteria. Materials and Methods: Silver NPs were biosynthesized in vivo with different alga species namely, Spirulina platensis, Chlorella vulgaris and Scenedesmus obliquus following two scenarios. First: by suspending a thoroughly washed algae biomass in $1 \mathrm{mM}$ aqueous $\mathrm{AgNO}_{3}$ solution. Second: by culturing them individually in culture media containing the same concentration of $\mathrm{AgNO}_{3}$. Silver NPs were characterized using UV-Vis spectroscopy, transmission electron microscopy (TEM), energy dispersive analysis (EDX) and Fourier transform infra-red (FTIR) spectroscopy. The biosynthesized silver NPs were tested for cytotoxic activity against a cancer promoter cyanobacteruim Microcystis aeruginosa, considering effects on cell viability and chlorophyll content. Results: The surface plasmon band indicated the biosynthesis of silver NPs at $\sim 400 \mathrm{~nm}$. Transmission electron microscopy (TEM) revealed that the silver NPs had a mean average size below $100 \mathrm{~nm}$. Energy-dispersive analysis X-ray (EDX) spectra confirmed the presence of silver element. FTIR spectral analyses suggested that proteins and or polysaccharides may be responsible for the biosynthesis of silver NPs and (-COO-) of carboxylate ions is responsible for stabilizing them. The toxic potentialities of the biosynthesized silver NPs against the cancer promoter cyanobacterium, Microcystis aeruginosa showed high reduction in viable cells count and the total chlorophyll content. Conclusions: The potential activity of the biosynthesized silver NPs from the studied algae species against Microcystis aeruginosa cells is expected to be mainly mediated by the release of silver ions $\left(\mathrm{Ag}^{+}\right)$from the particle surface and bioactive compounds as indicated by FTIR analysis.
\end{abstract}

Keywords: Biosynthesis - Microcystis aeruginosa - silver nanoparticles - toxic activities

Asian Pac J Cancer Prev, 15 (16), 6773-6779

\section{Introduction}

Cancer is already a major health problem. It is the second main cause of mortalities in the modern world after heart diseases, with more than 10 million new cases every year. This outline is expected to rise in the next few decades. In fact, around one in three people will be diagnosed with cancer throughout their lifetime (Siegel et al., 2012). The lifestyle changes suggest that the burden of neoplasia will become heavier over time, especially with increasing obesity and aging of what are now still youthful populations (Salim et al., 2009). The importance of environmental exposure to contaminants has also been highlighted (Safi, 2002).

Anthropogenic activities along with deficient water management have led to the enhancement of eutrophication in water bodies all over the world (Carmichael, 2007). Eutrophication processes plus specific environmental conditions can lead to cyanobacterial blooms, which are characterized by excessive proliferation of cyanobacterial cells that produce their toxins (deFigueiredo et al., 2004). Within the large family of cyanobacteria, the cancer promoting, Microcystis aeruginosa is the most common bloom-forming species that is able to produce cyanotoxin known as microcystin. Microcystin is one of the best studied classes of cyanobacterial toxins (Ouellette and Wilhelm 2003; Chen et al., 2009).

The risk of exposure to dissolved toxin immediately after the peak of a bloom must be addressed because cyanotoxins can persist even though the bloom has dissipated (Lawton et al., 1994). Prolonged exposure to sublethal doses of microcystin has been epidemiologically linked to primary liver cancer in humans (Yu, 1995).

The liver specificity of Microcystin is due to their selective uptake by hepatocytes through the membrane transport family, Organic Anion Polypeptide Transporters (OAPT) that mediates the uptake and elimination of numerous xenobiotics (Hagenbuch and Meier, 2003; Fischer et al., 2005). Microcystin-LR, inhibits protein phosphatases 1 and 2A(PP1 and PP2A), which are serine/ 
threonine phosphatases, sustains the phosphorylation of proteins and induces tumor promotion mediated through signal transduction, resulting in development of tumors. Humans are often exposed to these tumor promoters in the environment, the relationship between human cancer development and the presence of PP1 and PP2A inhibitors is a significant objective of cancer research (Fujiki and Suganuma, 2009).

Besides the liver, the effects of microcystins on other human organs including the kidneys and intestine (Hagenbuch and Meier, 2003), brain (Maidana et al., 2006), lungs (Soares et al., 2007) and reproductive system (Ding et al., 2006) have been investigated.

However, natural products including plant extracts and herbs have been used as medicine sources (Abu-Rabia, 2005; Liu et al., 2012). Nanotechnology opens new applications in many fields including medicine, material science, manufacturing and various technologies. Among all metallic nanoparticles, silver NPs have proved to be the most effective against large variety of organisms including cyanobacteria (Gong et al., 2007). The biological system for biosynthesis of silver NPs must be consisting of environmentally acceptable solvent system, eco-friendly reducing and capping agents (Vigneshwaran et al., 2007; Xie et al., 2007), high-yield, low cost, non-toxic and environmentally benign procedures (Thakkar et al., 2010).

At present, only few studies have investigated the interactions of silver NPs with cyanobacteria. Therefore, the rationale of this work was to investigate algae mediated synthesis of in vivo silver NPs, using three selected microalgae species belonging to different groups namely, Spirulina platensis, Chlorella vulgaris and Scenedesmus obliquus. The bio-reduction of $\mathrm{AgNO}_{3}$ ions in solution was confirmed and fully characterized. The potentialities of biosynthesized silver NPs was determined against the cancer promoter, Microcystis aeruginosa which can be further used as a mean of detoxification of water bodies contaminated by this cyanobacteruim in swimming pools.

\section{Materials and Methods}

\section{Source of algal strains and production of biomass}

The cyanobacterium Spirulina platensis and two green algae (Chlorella vulgaris and Scendesmus obliquus) were kindly provided from Phycology Laboratory, Faculty of Science, Alexandria University. Microcystis aeruginosa was obtained from Phycology laboratory, Faculty of Science, Tanta University, Egypt.S. platensis was cultured in BG- 11 medium for 15 days. Green algae were cultured in a modified Bold Basal medium (Jena et al., 2013). For the production of biomass, exponentially growing algae culture was transferred into fresh sterile medium $[10 \%$ (v/v) of inoculums], incubated at $28 \pm 2^{\circ} \mathrm{C}$ and day/night rhythm (1618), respectively. M. aeruginosa was cultured in 1 liter conical flasks containing $400 \mathrm{~mL}$ medium (Allen's and Stanier, 1968), and kept in controlled conditions of continuous light $(45 \mu \mathrm{mol} / \mathrm{ms})$ at $25 \pm 2{ }^{\circ} \mathrm{C}$.

In vivo Synthesis of silver NPs and their characterization

There were two methods used for the in vivo synthesis of silver NPs by algae cultures. The first method: algal cells from logarithmic phase were centrifuged at $4000 \mathrm{rpm}$ for $20 \mathrm{~min}$. The supernatant was removed and the biomass was washed with sterile deionized water to remove traces of media salts leftovers. The washing was repeated for five times (Jenal et al., 2013). The silver NPs were prepared by taking $5 \mathrm{gm}$ of algae biomass from an exponential growth phase in a $250 \mathrm{ml}$ Erlenmeyer flask with $95 \mathrm{ml}$ of $1 \mathrm{mM}$ aqueous $\mathrm{AgNO}_{3}$ solution (pH 7) (Sudha et al., 2013). According to the modified method of Devina Merin et al. (2010), the different algae species were individually cultured along with $1 \mathrm{mM} \mathrm{AgNO}_{3}$ solution and kept in the previously mentioned conditions for two weeks.

\section{Characterization of silver NPs}

The properties and structure of silver NPs have been characterized by means of vis-UV spectra of the solution, Transmission Electron Microscope (TEM) and EnergyDispersive analysis X-ray (EDX) spectrum as well as Fourier Transform Infrared Red spectroscopy (FTIR) spectral Analysis.

The bio-reduction of pure $\mathrm{Ag}^{+}$ions in aqueous solution was detected by sampling of aliquots $(0.2 \mathrm{~mL})$ of the colloidal suspension, and then diluting the samples with 2 $\mathrm{mL}$ deionized water and subsequently measuring Vis-UV spectra of the resulting diluents using UV-6800 UV VVis Spectrophotometer (JENWAY-Germany). The absorption maxima were scanned at the wavelength of 200-800 nm.

TEM analysis was employed to visualize the size and shape of silver NPs. TEM micrographs were taken by analyzing the prepared grids on (JEOL 100CX, Japan) at the Electron Microscope Unit- Faculty of ScienceAlexandria University.

The presence of elemental silver as well as the other elementary compositions of the silver NPs was detected. Energy-dispersive analysis X-ray (EDX) analysis was carried out at $20 \mathrm{KV}$ by X-ray micro-analyzer (Module Oxford 6587INCA X-sight) attached to JEOL 100CX Scanning electron microscopy.

Samples of the aqueous solution of the silver NPs were prepared by centrifugation at $10,000 \mathrm{rpm}$ for 30 min. The pellet was lyophilized and subjected to FTIR analysis by KBR pellets (FTIR grade) method (Kasthuri et al., 2009). The spectrum was recorded in the range of 500 to $4000 \mathrm{~cm}^{-1}$.

\section{Cytotoxic potentials of the biosynthesized silver NPs against M. aeruginosa}

Aliquots of $30 \mathrm{~mL}$ of the $M$. aeruginosa culture in growing media, Allen's and Stanier (1968) were exposed to $0.1,1$ and $10 \mathrm{mgL}^{-1}$ of the biosynthesized silver NPs and kept in controlled conditions of continuous light (45 $\mu \mathrm{mol} / \mathrm{ms})$ and temperature $\left(25 \pm 2^{\circ} \mathrm{C}\right)$ for $24 \mathrm{~h}$. Cell viability and total chlorophyll were determined. The experiments were conducted in triplicate and results are shown as the mean with standard deviations.

\section{Optical microphotographs of M. aeruginosa}

Morphological changes in $M$. aeruginosa culture exposed to $0.1,1.0$ and $10 \mathrm{mg} / \mathrm{L}$ of silver NPs for $24 \mathrm{~h}$ were determined using a Reichert microscope (Austria- Nr. 365475) and recorded with a Pixelink camera. 


\section{Determination of total chlorophyll}

Total chlorophyll was measured according to Tandeau de Marsac (1977); $2 \mathrm{ml}$ of the culture were centrifuged at $15.000 \mathrm{~g}$ for $10 \mathrm{~min}$ in a $2 \mathrm{ml}$ reaction tube. Then 1900 $\mu \mathrm{l}$ of the supernatant were removed and the cells were resuspended using an ultrasonic bath. Afterwards 900 $\mu \mathrm{l}$ of $100 \%$ methanol were added and incubated in the dark at $4^{\circ} \mathrm{C}$ for 1 hour. Samples were then centrifuged at $15.000 \mathrm{~g}$ for 10 minutes and absorption was measured at $650 \mathrm{~nm}$. Chlorophyll concentration in $\mu \mathrm{g} / \mathrm{ml}$ was calculated by the following formula: Chlorophyll $(\mu \mathrm{g} /$ $\mathrm{ml})=($ Abs $650 \times 13.9) / 2 \mathrm{ml}$.

\section{Evaluation of algal culture viability}

The $M$. aeruginosa cells viability was determined using Olympus BX41 fluorescence Microscope-America. Pictures were recorded using the USB camera with image capture software that is available for recording images.

\section{Results}

\section{Biosynthesis of silver NPs}

The biosynthesized silver NPs using the different microalgae strains were confirmed by the UV-Vis spectral analysis at various $\mathrm{nm}$. The colour change was due to excitation of Surface Plasmon Vibration which indicated the formation of silver NPs (Figure 1).

\section{Characterization of silver NPS}

UV-Visible (UV-Vis) spectral analysis: The Surface Plasmon band indicated the production of silver NPs at $\sim 400 \mathrm{~nm}$ for $S$. platensis and C. vulgaris as well as $S c$. obliquus, respectively. These results revealed that the silver NPs were dispersed in the aqueous solution with no evidence for aggregation (Figure 1).

Transmission electron microscope (TEM): The biosynthesis of silver NPs was further confirmed by the structural view and determination of the size of nanoparticles under the TEM as shown (Figure 2). Most of the biosynthesized silver NPs seem to be spherical in

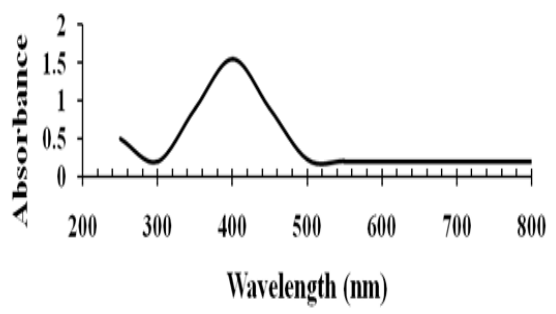

Figure 1. UV-Vis Spectrum of Plasmon Resonance of the Biosynthesized Silver NPs

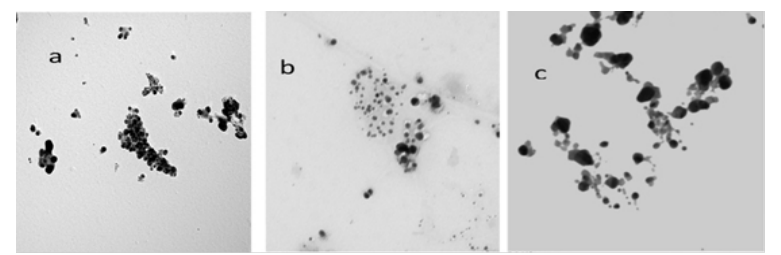

Figure 2. Transmission Electron Micrographs of the biosynthesized silver NPs using $S$. platensis, a) C vulgaris; b) and $S c$. obliquus; c) respectively (magnification: 10000x) morphology and well distributed with the mean average size of $20.8 \pm 4,8.2 \pm 3$ and $8.8 \pm 2 \mathrm{~nm}$ for $S$. platensis, $C$. vulgaris and Sc. obliquus, respectively.

Energy-dispersive analysis X-ray (EDX) spectrum: The presence of elemental silver is further confirmed by Energy-dispersive analysis X-ray (EDX) spectra with the absorption peak in the range of 3 to $4 \mathrm{keV}$ as outlined in (Figure 3). However, some of the additional peaks for $\mathrm{C}$, $\mathrm{Cu}, \mathrm{N}, \mathrm{O}, \mathrm{P}, \mathrm{Mg}, \mathrm{S}$, and Ca were observed.

Fourier Transform Infra-red (FTIR) analysis: FTIR analyses were carried out to identify the possible biomolecules responsible for the reduction of silver ions and the capping of the bioreduced silver NPs synthesized by different micro algal species. Figure 4(a) shows FTIR spectrum of silver NPs synthesized using S. platensis. The peak at $3396 \mathrm{~cm}^{-1}$ is mainly due to N-H stretching vibration presence of secondary amines (protein, lipid), the peak at $1639 \mathrm{~cm}^{-1}$ can be assigned to the protein amide I band, mainly $v(\mathrm{C}=\mathrm{O})$ stretching and may be due to the $\mathrm{N}-\mathrm{H}$ bending vibration present in the carbonyl $\beta$ unsaturated

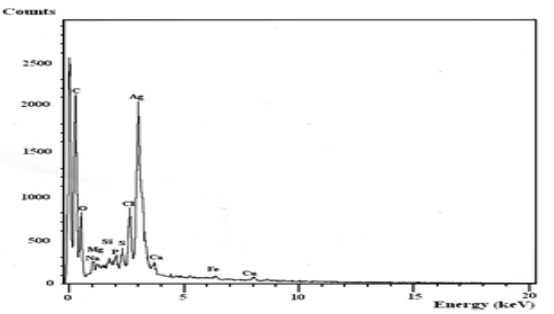

Figure 3. EDX Monographs of the Biosynthesized Silver NPs Showing Elemental Silver in High Signals
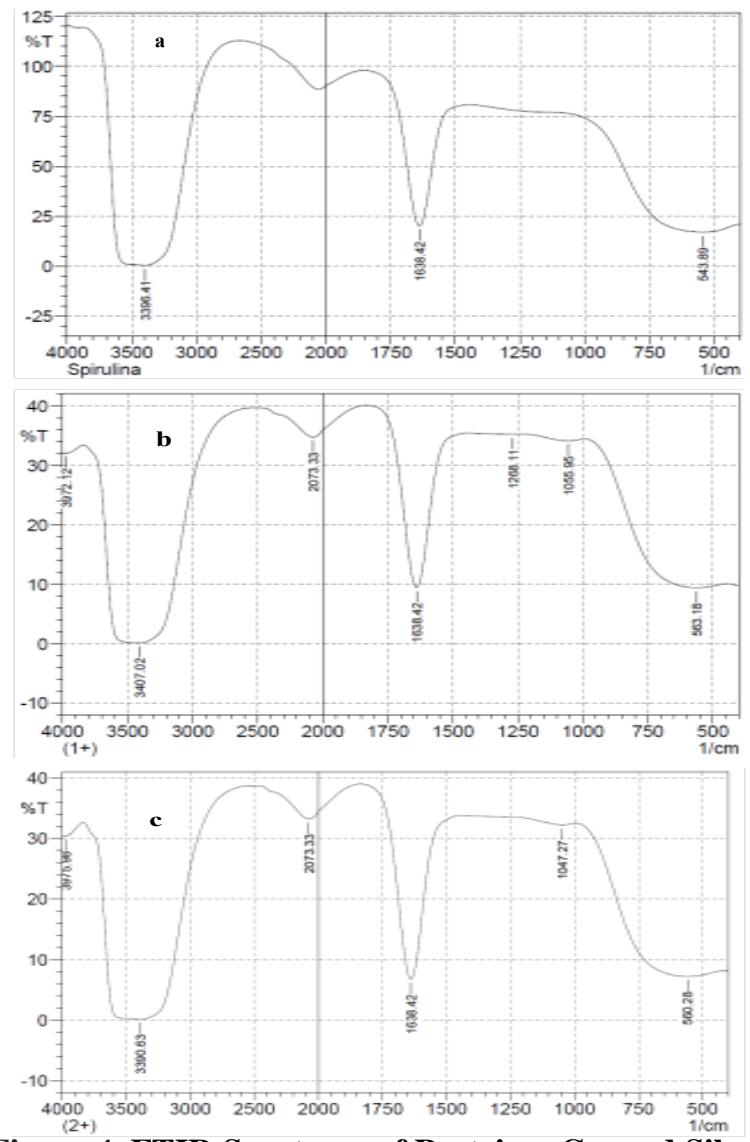

Figure 4. FTIR Spectrum of Protein - Capped Silver

NPs Synthesized using S. platensis. a) C. vulgaris; b) and Sc.obliquus; c) respectively 
Mostafa Mohamed El-Sheekh and Hala Yassin El Kassas

ketone amide and the peak at $544 \mathrm{~cm}^{-1}$ may be due to C-I stretching vibration presence of Iodo compounds.

Figures 4(b) and 4(c) show FTIR spectrum of silver NPs synthesized using $C$. vulgaris and Sc. obliquus. Stretching vibrations of proteins were observed by two clear bands. The peaks at 3390 and $3407 \mathrm{~cm}^{-1}$ correspond to Protein v (N-H) stretching (amide A), for C. vulgaris and $S c$. obliquus, respectively. The other peak at 1638 $\mathrm{cm}^{-1}$ presented in the 2 spectra is due to Protein amide I band mainly $v(\mathrm{C}=\mathrm{O})$ stretching. However the peak at 2073
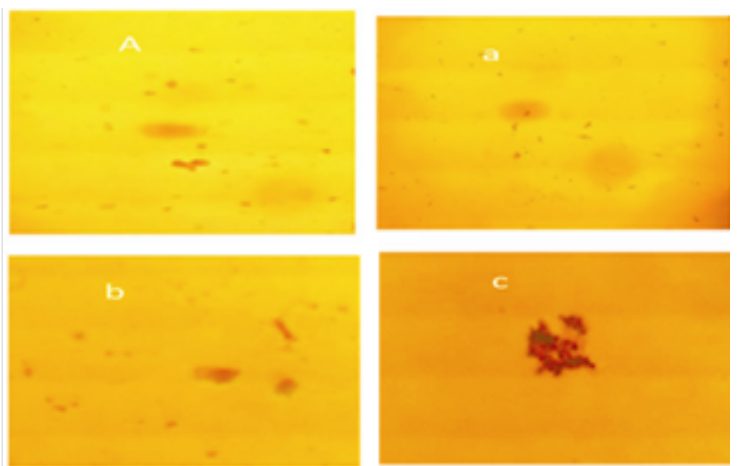

Figure 5. Morphological Changes of M. aeruginosa Colonies Showing Control Cells (A) and Images of Cells Exposed to $10 \mathrm{mgL}^{-1}$ of Silver NPs Synthesized using $S$. platensis, a; and $C$. vulgaris, $b$; as well as $S c$. Obliquus, c; Respectively

A)
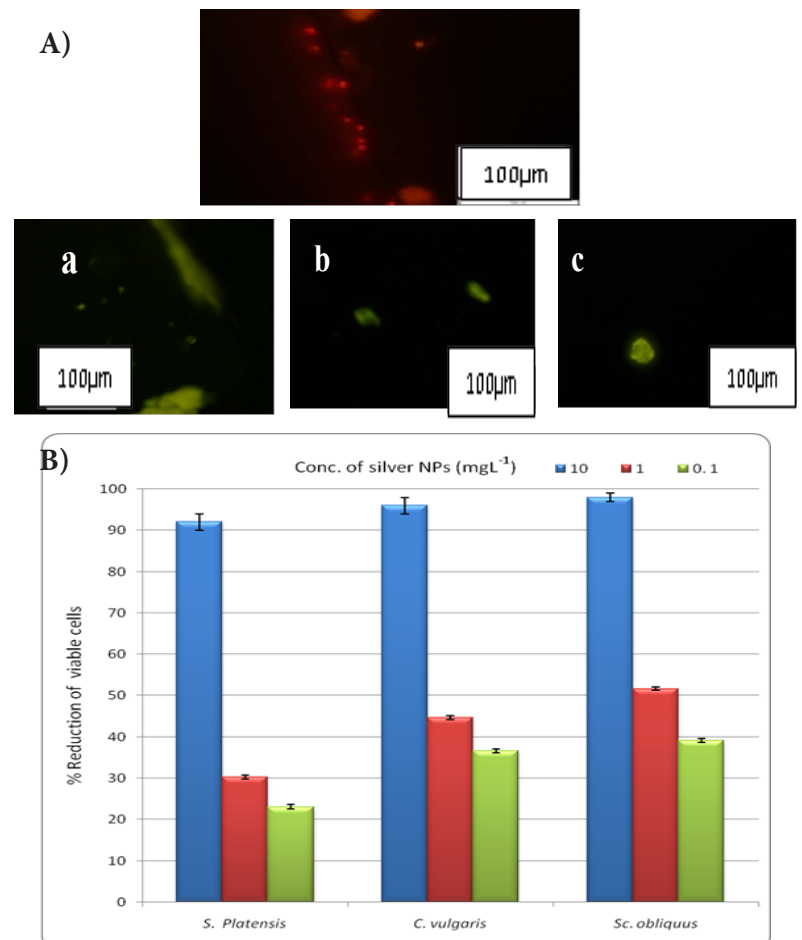

Figure 6. A) Images of Cells Showing Control $M$. aeruginosa Cells (A) and Images of Cells Exposed to $10 \mathrm{mgL}^{-1}$ of Silver NPs Synthesized using $S$. platensis, a; C. vulgaris, b; and Sc. obliquus, c; respectively. [Red fluorescence is caused by chlorophyll and represents viable cells. Non-viable cells show green unspecific auto fluorescence]. B) Percent Reduction of Viable Cells of M. aeruginosa Under the Stress of Different Concentrations of Silver NPs for 24h $\mathrm{cm}^{-1}$ may be assigned to Transition metal carbonyls. The band at $1047 \mathrm{~cm}^{-1}$ is due to Symmetric C-H Stretching vibration, presence of Antioxidant enzyme, Carbohydrate $v(\mathrm{C}-\mathrm{O}-\mathrm{C})$ of polysaccharides. However, the peak observed at $1268 \mathrm{~cm}^{-1}$ may be assigned to the presence of $\mathrm{C}-\mathrm{O}$ asymmetric $\mathrm{C}-\mathrm{O}-\mathrm{C}$ stretching presence of esters. The band at $1055 \mathrm{~cm}^{-1}$ corresponds to Carbohydrate $v(\mathrm{C}-\mathrm{O}-\mathrm{C})$ of polysaccharides. Peaks at $560 \mathrm{~cm}^{-1}$ and $563 \mathrm{~cm}^{-1}$ represents C-I stretching vibration presence of Iodo compounds.

The cytotoxic activity of the biosynthesized silver NPs M. aeruginosa cells

Cell viability assay: Cultures of the tumor promoting cyanobacteruim, $M$. aeruginosa exposed to different concentrations of the biosynthesized silver NPs for 24h showed cell aggregates' formation compared to control (Figure 5). Large aggregates were observed in the algal culture under the stress of $10 \mathrm{mgL}^{-1}$ for all the biosynthesized silver NPs.

The percent reduction of cyanobacteria cells' viability, reveal a reduction in viable cells after $24 \mathrm{~h}$ treatment. Growth of M. aeruginosa under the stress of 1 to $10 \mathrm{mgL}^{-}$ ${ }^{1}$ biosynthesized silver NPs resulted in a significant reduction of viable cells (Figures 6A \& 6B). The exposure

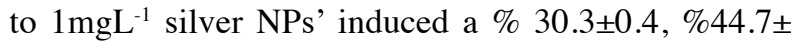
0.5 and a $\% 51.1 \pm 0.4$ decrease of viable cells, for those silver NPs produced by $S$. platensis, $C$. vulgaris, and $S c$. obliquus, respectively. As the concentration of silver NPs increased, the cyanobacteria cells' viability was decreased. High reduction of the viable cell count was achieved by using $10 \mathrm{mgL}^{-1}$ of the biosynthesized silver NPs. The percentages of reduction of viable cells reached $\% 92 \pm 2.0$, $\% 96 \pm 3.0$ and $\% 98 \pm 2.0$ for the silver NPs produced by S. platensis, C. vulgaris and Sc.obliquus, respectively.

\section{Effect of silver NPs on chlorophyll content}

The reduction levels in chlorophyll content of the tumor promoting cyanbacterium cells exposed to different concentrations of the biosynthesized silver NPs for 24 hours are presented in Figure 7. The results show that using silver NPs produced by $S$. platensis, $C$. vulgaris and Sc. obliquus, have reduced the chlorophyll content of cyanobacterium by $\% 20.3 \pm 0.4, \% 34.7 \pm 0.3$, and $\% 41.1 \pm 0.5$ respectively. Increasing the silver NPs

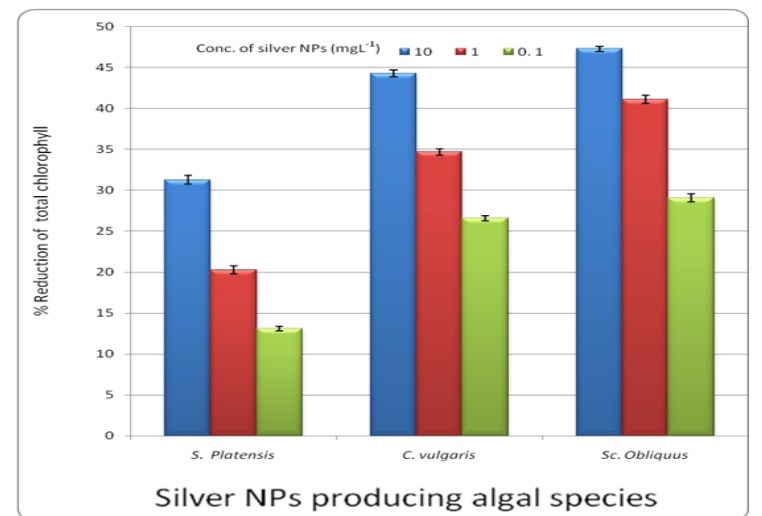

Figure 7. Percent Reduction of Chlorophyll Content of $M$. aeruginosa Under the Stress of Different Concentrations of Silver NPs for $24 \mathrm{~h}$ 
concentrations have caused more pronounced decrease in the chlorophyll content. The application of silver NPs (10.0 $\left.\mathrm{mgL}^{-1}\right)$ produced by Sc. obliquus led to the highest reduction of the total chlorophyll content of M.aeruginosa by $47.3 \% \pm 0.3$.

\section{Discussion}

Due to their unique physical and chemical properties, nanomaterials are extensively studied. Natural nanoparticles (NP) were investigated for their physicochemical behavior in the environment (Buffle, 2006; Novak and Bucheli, 2007), but less for human health and environmental consequences with the exception of small-sized dust particles (Yin et al., 2013).

As observed in this study one of the possible roles of the microorganisms is providing a multitude of nucleation centers; establishing conditions for obtaining highly dispersed nanoparticle systems. In addition, using microorganisms in green biosynthesis of nanoparticles slow down aggregation, or entirely prevent it by immobilizing the particles and providing viscous medium (Sun and Xia, 2002). Thus the biosynthesized nanoparticles have highly intricate architectures and are ordered during assembly.

The biosynthesized silver NPs were monitored by UV-Vis spectrophotometer at various nm-s. The surface Plasmon band in the silver NPs solution remained close to $400 \mathrm{~nm}$ throughout the reaction period indicating that the particles are dispersed in the aqueous solution, with no evidence for aggregation. The silver ions are reduced by the extracellular reductase enzymes produced by the microorganisms to silver metal in nanometer range (Sosa et al., 2003; Fu et al., 2006). The exact mechanism leading to the formation of silver NPs by the algal biomass is not fully understood; there are still several possible mechanisms involved in the process. It is thought that the first step involves the trapping of metal ions on the surface of algal cells, possibly via electrostatic interaction between the ions and negatively charged carboxylate groups present in the cell surface. Thereafter, the ions are reduced by the enzymes, leading to the formation of nuclei, which subsequently grow through the further reduction of metal ions and accumulation of these nuclei (Mandal et al., 2006).

TEM images of the different silver NPs reveal that the silver NPs seem to be spherical in morphology and well distributed with an average size of $20.8 \pm 4.0 ; 8.2 \pm 3.0$ and $8.8 \pm 2.0 \mathrm{~nm}$ for $S$. platensis and C. vulgaris as well as $S c$. obliquus, respectively. Similar results were reported by Jena et al. (2013).

The EDX spectrum of the biosynthesized silver NPs confirmed the presence of elemental silver. The presence of an optical absorption band at $3 \mathrm{KeV}$ reveals the presence of pure metallic silver NPs. The other peaks may be due to proteins and cell biomass trapping the silver NPs (Jain et al., 2011).

FTIR measurements were carried out to identify the biomolecules which may be responsible for synthesis and stabilization of silver NPs. FTIR analyses revealed the presence of molecules like proteins, lipids and carbohydrates. Stretching vibrations of proteins were observed by strong bands in the spectrum of silver NPs synthesized by the three algae species. In accordance with these results, Sable et al. (2012) stated that representative spectra of biosynthesized silver NPs manifest absorption peaks of respective functional groups and indicated the presence of stabilized protein molecules. Moreover, Govindaraju et al. (2008) suggested the interaction of single cell protein of $S$. platensis with aqueous silver nitrate $\left(\mathrm{AgNO}_{3}\right)$ for the synthesis of silver NPs. The conformation of protein molecules plays an important role in silver NPs synthesis and stabilization. The results suggested that the capping ligand of the silver NPs may be an aromatic compound. It was reported that the extract of unicellular green algae $C$. vulgaris was used to synthesize single-crystalline silver nanoplates at room temperature (Xie et al., 2007). Proteins in the extract provide dual function of $\mathrm{Ag}+$ reduction and shape-control in the synthesis of the silver NPs. Up to the current knowledge, this is the first report that concluded the biosynthesis of silver NPs by Sc.obliquus.

It was concluded from protein assay of microorganisms that the preparation of silver NPs is a NADH-dependent reductase. The reductase enzyme gains electrons from $\mathrm{NADH}$ and oxidizes it to NAD+. The enzyme is then oxidized by the simultaneous reduction of silver ions forming silver metal in nano form. In some cases a nitrate-dependent reductase is responsible for the bioreduction process, therefore a complex electron shuttle materials may be involved in the biosynthesis process (Moghaddam, 2010). Moreover, (-COO-) of carboxylate ions is responsible for stabilizing the silver NPs. It was reported that extracts from microbes act both as reducing and capping agents in metal synthesis of nanoparticles. Reduction of metal ions by combinations of biomolecules such as enzymes or proteins, amino acids, polysaccharides, and vitamins (Collera-Zuniga et al., 2005) which may be used as reductants to react with silver ions, leading to silver NPs synthesis in solutions ( $\mathrm{Li}$ et al., 2007) is environmentally benign, yet chemically complex. The overall suggestions are that proteins and polysaccharides were involved in the reduction of $\mathrm{AgNO}_{3}$ to form silver NPs and the capping agents may be the aromatic compounds.

The cytotoxicity of silver NPs is expected to be mediated mainly by the release of silver ions $(\mathrm{Ag}+)$ from the particle surface. Consequently, silver NPs can be considered as a source of toxic $\mathrm{Ag}+$, which are adsorbed to particle surfaces or formed upon oxidative dissolution in presence of oxygen, ligands, or organisms (Navarro et al., 2008; Xiu et al., 2011).

In the present study, the cultures of the cancer promoter cyanobateruim, M. aeruginosa exposed to different concentrations of the biosynthesized silver NPs for $24 \mathrm{~h}$ showed formation of cell aggregates comparing to control cultures. Large aggregates were observed in the algal cultures under the stress of $10 \mathrm{mgL}^{-1}$ after administration of all biosynthesized silver NPs. In this respect, it was reported that metal nanoparticles like $\mathrm{TiO}_{2} \mathrm{NPs}$ were able to interact directly with the cells' surface through adsorption to the cell walls (Sadiq et al., 2011). The pores 
across the cell wall have diameters ranging from 5 to $20 \mathrm{~nm}$ that determines its sieving properties, the biosynthesized silver NPs have diameters within the mentioned range. It was suggested that the formation of aggregates might inhibit cells' growth (Navarro et al., 2008). The strong reduction of viable cells count and chlorophyll content further support this suggestion. Cyanobacterium cells' viability, evaluated by fluorescent microscope, revealed a reduction in viable cell number after $24 \mathrm{~h}$ treatment. As the concentration of the biosynthesized silver NPs was increased, the algal cells' viability was sharply decreased. The percent reduction of viable cells reached $98 \%$ for the silver NPs produced by Sc. obliquus.

The chlorophyll concentration is often used as a measure for the viability of cyanobacteria cultures (Schulze et al., 2011). The data of the present study have shown an expected dose dependent decrease of the chlorophyll concentrations for all the samples along with decreased numbers of viable cells due to silver NPs administration. It was established that chlorophyll auto fluorescence could be accepted as the most convenient method for differentiation between living and dead cells. The tests based on the fluorescence of the dead cell cytoplasm appeared to be useful for vitality assessment, because chlorophyll fluorescence was lost and did not mask cytoplasmic fluorescence (Pouneva 1997). Interestingly, increasing the concentrations of silver NPs have caused more decreasing in the chlorophyll content of the studied Cyanobacterium. The chlorophyll concentration also matched the results of the viability analysis via fluorescence. These findings are in agreements with those of Schulze et al., (2011).

In line with the present results, many studies have investigated the cytotoxic effects of metal nanoparticles against different human cancer cell lines (Rosarin et al. 2013). El-Kassas and Attia, (2014) reported the cytotoxic activity of biosynthesized silver nanoparticles with an extract of the red seaweed Pterocladiella capillacea on the HepG 2 cell line. In addition El-Kassas and El-Sheekh, (2014), studied the cytotoxic activity of gold nanoparticles of Corallina officinalis on human breast cancer (MCF-7) cell line. Other investigations are necessary to improve the particle size and other necessary features of the biosynthesized nanoparticles. The results of this work provided strong evidence for the consideration of silver nanoparticles (AgNPs) as antialgal agent against the liver inducing cancer $M$. aeruginosa. Such positive environmental and toxicological applications will be imperative to ensure the nanomaterials design process yields both effective and safe technologies for prevention of liver cancer in human as results of the toxin excreted by $M$. aeruginosa.

\section{Acknowledgements}

The authors would like to thank Prof. Dr. Elsayed I. Salim, the Professor of Cell, Genetics \& Molecular Carcinogenesis at Tanta University, Faculty of Science, Egypt, for critical reading of the manuscript.

\section{References}

Abu-Rabia A (2005). Herbs as a food and medicine source in Palestine. Asian Pac J Cancer Prev, 6, 404-7.

Allen's MM, Stanier S T (1968) Selective isolation of blue-green algae from water and soil. J Gen Microbiol, 51, 302.

Buffle J (2006). The key role of environmental colloids/ nanoparticles for the sustainability of life. Environ Chem, 3, 155-8.

Carmichael W (2007). A world overview one-hundred twentyseven years of research on toxic cyanobacteria where do we go from here? In: Kenneth Hudnell H, editor. Proc interagency, international symposium on cyanobacterial harmful algal blooms. Adv Exp Med Biol, 95-115.

Chen W, Peng L, Wan N, et al (2009). Mechanism study on the frequent variations of cell-bound microcystins in cyanobacterial blooms in Lake Taihu: implications for water quality monitoring and assessments. Chemosphere, 77, 1585-1593.

Collera-Zuniga O, Jimenez FG, Gordillo RM (2005). Comparative study of carotenoid composition in three mexican varieties of Capsicum annuum L. Food Chem, 90, 109-14.

deFigueiredo DR, Azeiteiro UM, Esteves SM, et al (2004). Microcystin producing blooms- a serious global public health issue. Ecotoxicol Environ Safety, 59, 151-63.

Devina Merin D, Prakash S, Valentine Bhimba B (2010). Antibacterial screening of silver nanoparticles synthesized by marine micro algae. Asian Pac J Trop Med, 3, 797-9.

Ding XS, Li XY, Duan HY, et al (2006). Toxic effects of microcystis cell extracts on the reproductive system of male mice. Toxicon, 48, 973-9.

El Kassas HY, Attia AA (2014). Bactericidal application and cytotoxic activity of biosynthesized silver nanoparticles with an extract of the red seaweed Pterocladiella capillacea on the HepG2 cell line. Asian Pac J Cancer Prev, 15, 1299-306.

El Kassas HY, El-Sheekh MM (2014). Cytotoxic activity of biosynthesized gold nanoparticles with an extract of the red seaweed Corallina officinalis on human breast cancer (MCF-7) cell line. Asian Pac J Cancer Prev, 15, 4311-7.

Fischer H, Kloep F, Wilzcek S, et al (2005). A river's liver -microbial processes within the hyporheic zone of a large low land river. Biogeochemistry, 76, 349-71.

Fu M,Li Q, Sun D, et al (2006). Rapid preparation process of silver nanoparticles by bioreduction and their characterizations. Chin J Chem Engin, 14, 114-7.

Fujiki H, Suganuma M (2009). Carcinogenic aspects of protein phosphatase 1 and 2A inhibitors. Prog Molec Subcell Biol, 46, 221-54.

Gong P, Li H, He X, et al (2007). Preparation and antibacterial activity of Fe3O4- Ag nanoparticles. Nanotechnology, 18, 604-11.

Govindaraju K, Basha S K, Kumar VG, et al (2008). Silver, gold and bimetallic nano particles production using single cell protein (Spirulina platensis). J Material Sci, 43, 5115-22.

Hagenbuch B, Meier PJ (2003). The superfamily of organic anion transporting polypeptides. Biochim Biophys Acta, 1609, 1-18.

Jain N, Bhargava A, Majumdar S, et al (2011). Extracellular biosynthesis and characterization of silver nanoparticles using Aspergillus flavus NJP08: A mechanism perspective. Nanoscale, 3, 635-41.

Jena J, Pradhan N, Dash BP, et al (2013). Biosynthesis and characterization of silver nanoparticles using microalgae Chlorococcum humicola and its antibacterial activity. Int $J$ Nanomater Biostruct, 3, 1-8. 
Kasthuri J, Veerapandian S, Rajendiran N (2009). Biological and synthesis of silver and gold nanoparticles using apiin as reducing agent. Colloids SurfacesB: Biointerfaces, $\mathbf{6 8}$, $55-60$.

Lawton LA, Edwards C, Codd A (1994). Extraction and high-performance liquid chromatographic method for the determination of microcystins in raw and treated waters. Analyst, 119, 1525-30.

Li S, Shen Y, Xie A, et al (2007). Green synthesis of silver nanoparticles using Capsicum annuum L extract. Green Chem, 9, 852-85.

Liu W, Li SY, Huang XE, et al (2012). Inhibition of tumor in vitro by a combination of extracts from Rosa roxburghii tratt and Fagopyrum cymosum. Asian Pac J Cancer Prev, 13, 2409-14.

Maidana M, Carlis V, Galhardi FG, et al (2006). Effects of microcystins over short- and long-term memory and oxidative stress generation in hippocampus of rats. ChemBiol Interact, 159, 223-34.

Mandal D, Bolander ME, Mukhopadhyay D, et al (2006). The use of microorganisms for the formation of metal nanoparticles and their application. Appl Microbiol Biotechno, 69, 485-92.

Moghaddam KM (2010). An introduction to microbial metal nanoparticle nano structured materials. Mater Sci Forum, 293, 83-98.

Navarro E, Piccapietra F, Wagner B, et al (2008). Toxicity of silver nanoparticles to Chlamydomonas reinhardtii.Environ Sci Technol, 42, 8959-64.

Novak B, Bucheli T (2007). Occurrence, behavior and effects of nanoparticles in the environment. Environ Pollut, 150, 7-22.

Ouellette AJA, Wilhelm SW (2003). Toxic cyanobacteria: the evolving molecular toolbox. Frontiers Ecol Environ, 7, 359-66.

Pouneva I (1997). Evaluation of algal culture viability and physiological state by fluorescent microscopic methods. Bulg J Plant Physiol, 23, 67-76.

Rosarin, FS, Arulmozhi V, Nagarajan S, Mirunalini S (2013) Antiproliferative effect of silver nanoparticles synthesized using amla on Hep2 cell line. Asian Pac J Trop Med, 6, 1-10.

Sable N, Gaikwad S, Bonde S, Gade A, Rai M (2012). Phytofabrication of silver nanoparticles by using aquatic plant Hydrilla verticilata. Nusantara Bioscience, 4, 45-9.

Sadiq IM, Dalai S, Chandrasekaran N, Mukherjee A (2011). Ecotoxicity study of titania $\left(\mathrm{TiO}_{2}\right)$ NPs on two microalgae species: Scenedesmus sp. and Chlorella sp. Ecotox Environ Safe, 74, 1180-7.

Safi JM (2002). Association between chronic exposure to pesticides and recorded cases of human malignancy in Gaza Governorates (1990-1999). Sci Total Environ, 284, 75-84.

Salim EI, Moore MA, Al-Lawati JA, et al (2009). Cancer epidemiology and control in the Arab world-past, present and future. Asian Pac J Cancer Prev, 10, 3-16.

Schulze KA, Lopez D, Tillich UM, et al (2011). A simple viability analysis for unicellular cyanobacteria using a new autofluorescence assay, automated microscopy, and image. J BMC Biotechnol, 11, 118.

Siegel R, Naishadham D, Jemal A (2012). Cancer statistics, 2012. CA. Cancer J Clin, 62, 10-29.

Soares M, Cagido VR, Ferraro RB, et al (2007). Effects of microcystin-LR on mouse lungs. Toxicon, 50, 330-38.

Sosa IOC, Noguez RG, Barrera J (2003). Optical properties of metal nanoparticles with arbitrary shapes. J Phys Chem B, 107, 6269-75.

Sudha S, Karthic RS, Rengaramanujam J (2013). Microalgae mediated synthesis of silver nanoparticles and their antibacterial activity against pathogenic bacteria. Ind $J$ Experim Biol, 52, 393-9.
Sun Y, Xia Y (2002). Shape-controlled synthesis of gold and silver nanoparticles. Science, 298, 2176-9.

Tandeau de Marsac, N (1977). Occurrence and nature of chromatic adaptation in preparation method. J Young Investigators, 19, 1-7.

Thakkar KN, Mhatre SS, Parikh R Y (2010). Biological synthesis of metallic nanoparticles. Nanomedicine: Nanotechnology Biology Medicine, 6, 257-62.

Vigneshwaran N, Ashtaputre NM, Varadarajan PV, Nachane RP, Paraliker KM (2007). Balasubramanya rh, biological synthesis of silver nanoparticles using the fungus Aspergillus flavus. Mater Lett, 61, 1413-8.

Xie J, Lee JY, Wang DIC, et al (2007). Silver nanoplates: from biological to biomimetic synthesis. ACS nano, 1, 429-439.

Xiu ZM, Ma J,Alvarez PJJ (2011). Differential effect of common ligands and molecular oxygen on antimicrobial activity of silver nanoparticles versus silver ions. Environ Sci Technol, 45, 9003-8.

Yin HT, Zhang DG, Wu XL, et al (2013). In vivo evaluation of curcumin-loaded nanoparticles in a A549 xenograft mice model. Asian Pac J Cancer Prev, 14, 409-12.

Yu SZ (1995). Primary prevention of hepatocellular carcinoma. $J$ Gastroenterol Hepatol, 10, 674-82. 